\title{
Evaluation of Cost Management Controlling System in Petroleum Enter- prise
}

\author{
Dan Guo* and Changqing Zhang
}

\author{
College of Accountant, Heilongjiang Bayi Agricultural University, Daqing, Heilongjiang, 163319, P.R. China
}

\begin{abstract}
In this paper, a model of cost management controlling system was established for implementation and supervision of strategic management in petroleum enterprise. Using this model, various controlling methods are divided into five grades under different strategies. Each grade is assigned a value by the expert scoring method, and the scores of cost management controlling system could be calculated. If the score is greater than zero, the cost management controlling system will have a positive effect on strategy; if the score is less than zero, it will have a negative effect on strategy. With the method proposed, the cost management evaluation of the fourth oil recovery company of Daqing Oilfield was carried out and the results were reasonable.
\end{abstract}

Keywords: Cost, Cost avoidance, Cost control, Cost management, Evaluation.

\section{INTRODUCTION}

Cost management evaluation is a kind of scientific value judgment about production and operation, with specific indicators and standards, for achieving cost management objectives and the ultimate goal. It is the core part of cost management controlling system. It sets the direction for supervisors and employees, and lays the necessary foundation for incentive mechanism effective operating. Cost management controlling system evaluation is the integral part of evaluation system, referring to cost management methods.

Research has been continued on cost management controlling system evaluation. There are many research achievements such as investment center performance evaluation by using indicators including rate of income on investment, residual income, Economic Value Added(EVA) and non-financial indicators in the middle of the $1960 \mathrm{~s}$ [1]; input and output evaluation by local production efficiency, complete production efficiency, operating production efficiency and process production efficiency in the middle of the 1980s $[2,3]$; performance evaluation based on activity by business processes value analysis from three respects including efficiency, quality and time in the early 1990s [4-8]; strategic cost management evaluation by Balanced Scorecard Card(BSC) in the end of the 20th century [9]. The thinking of cost management performance evaluation was summarized by Professor Xuying Yu in 1994 [10]. Cost management process evaluation was put forward by Professor Heai Huang in 1998 [11]. A model of comprehensive evaluation on cost management level was proposed by Professor Xijiang Guo in 1999 [12]. An integrated evaluation method was provided by Professor Qiaogen Feng in 2002 [13]. It is proposed that matching cost management with enterprise management strategies should be applied to cost management evaluation [14].

*Address correspondence to this author at the College of Accountant, Heilongjiang Bayi Agricultural University, Daqing, Heilongjiang, 163319, P.R. China; Tel: 13945901023; E-mail: guodan2007@163.com
Many defects exist in the current methods, such as overgeneralization and lack of the guidance to the enterprise market competition.

\section{COMPONENT ANALYSIS OF COST MANAGE- MENT CONTROLLING SYSTEM}

Controlling system contains all the cost management activities except cost calculation. It consists of two levels, cost avoidance and cost control. Cost avoidance means to cost as little as possible in activities, and then avoid the unnecessary costs. Cost control means to increase the availability of cost, which is inevitable. In this paper, cost management controlling system will be analyzed at two levels mentioned above.

\subsection{Cost Avoidance}

Based on the definition of cost avoidance and the characteristics of various cost management methods, we should summarize cost avoidance methods as shown below.

1) Origin management: Origin management is to focus administration on the origins of the costs in daily management and to emphasize the supervision of the origin. The origins of costs include time origin, space origin and operation procedure. The basic conditions of costs are situated on the intersection of origins above. They are the nature of the economic resources which could be utilized and become the connections between each other. They consist of the technical performance of means of labor, the quality standard of object of labor, the skill and quality of laborer, technical standard of products, organizational structure of enterprise, segregation of duties, management system, corporate culture and key external relationships. Costs could be reduced continuously by improving the basic conditions of costs.

2) Value Engineering: Value Engineering is a kind of management technology and a method of thought. It contains a series of organized activities which focuses on function 
analysis, in order to achieve the necessary function of products and operations stably at the lowest cost. The main ideas of Value Engineering are to extract the maximum products value at the minimum costs, to reduce cost by functional analysis and to get rid of "surplus quality" and "exorbitant cost" by value analysis [15]. From the perspective of the cost avoidance, application of Value Engineering is Target Costing. VE consists of marketing value engineering presenting products information based on originality, designing value engineering controlling improvement by feasibility analysis and optimum analysis and manufacturing value engineering improving continuously in the process of manufacturing.

3) Activity improvement: Activity refers to the process of resource consumption in order to provide certain products or services within an organization. We call resource consumption in the activities activity cost. The completion of activities should consume resources so that products value would be given. The products value given would be transferred to the next activity. It is repeated in order to promote manufacturing process, until the final process were completed and product was sold to consumers. It shows that product manufacturing process, known as process of valuing, contains products consuming activities and activities consuming resources [16]. Based on cost management, activities are divided into value-added and non-value-added. Maximizing valueadded efficiency has the roles to avoid cost. Consequently, activity improvement by any means to maximize value-added efficiency is the embodiment of cost avoidance.

4) Activity chain optimization: Resources are consumed continuously in the production operation. As long as resources are consumed, the activities are there [17]. Some activities could be combined into one in order to simplify the calculation. The production can be recognized as the transfer between activities. So activities costs could be divided into two parts, one is the cost in activities and the other is the cost between activities. In some cases, the cost in activities is not high, not waste and even considerable saving, nevertheless most is consumed in the transmission [18]. Thus, the reasonable arrangement for the transmission between activities, reduction or even elimination of the transmission are effective methods of cost avoidance. Macroscopically speaking, from the perspective of value chain, value chain is activity chain. It is an inconvenient truth that cost avoidance could be achieved by optimizing the value chain [19]. Therefore, this article classified value chain optimization as activities chain optimization.

5) Other methods of cost avoidance: In addition to the cost avoidance methods above, common methods include the rational use of capital and human resource. Capital plays a very important role in daily business. We can streamline capital utilization, increase capital utilization efficiency, control and supervise capital flows for more rationalization and legalization, prevent unreasonable expenses strictly and spend resources smartly, to avoid idling assets, wasting money, occupying production funds, blind construction and blind procurement [20]. The rational allocation and utilization of human resources refers to a series of activities which destination is not only the preservation and increase of human capital value, but also the maximization of team contribution and organization benefits. The activities are including establishing a particular technology structure, reserving human resource by means of strategic investment, establishing the incentive mechanism and integrating resources.

\subsection{Cost Control}

Based on the definition of cost control and the characters of cost management methods, the cost control methods are shown as follows.

1) Budget management: Budget management in short is a plan made to achieve business goals. It is important to guide the steady production. Therefore, budget management is the first to be discussed [21]. Budget is the quantitative description of operation scheme. It shows operation plan with figures and tables, which is used as a basis for controlling activities and evaluating result. The methods of budgeting consist of flexible budget (A budget aiming at the problem of fixed budget, is based on quantitative relation between different items, such as revenues, costs, expenses and activities), zero-base budget (A budget starting from scratch, calculates any cost from zero, not considering the data base) and rolling budget (A budget keeping a span of 12 months, completes the next month's budget instead of the beginning one by a rolling way).

2) Cost variance analysis: Cost variance analysis on one hand regulates the variance between planning and execution in daily operation for short-term objectives, on the other hand further analyzes daily variance to improve the goals and schemes in the course of continuing operations, which would provide the basis of long-term benefits. Cost variance analysis consists of target cost control, standard cost system and cost analysis [22]. Target cost control, a method of target management, is strictly limiting, supervising and guiding each cost with reference to target cost, to obtain the biggest economic benefits with minimal cost. Standard cost system is to compare the actual data with standard and then find out the reasons for difference. Cost analysis refers to analyzing daily cost difference collected in order to provide improvement advice for next cost cycle.

3) Performance evaluation system and incentive mechanism: Performance evaluation system and incentive mechanism are essential. Performance evaluation system should have an insight into organizational activities, while incentive mechanism should be implemented to motivate all staff to work harder for the ultimate objective [23]. Performance evaluation includes a series of activities. Senior managers set standards for department managers by budgeting and planning, and then measure performance for inspection. Measuring the performance of each departments in organization is a prerequisite for the allocation of resources in the organization. When a new business is started, it helps senior managers to allocate subsequent resources to forecast revenues, costs and investment, then compare actual data and budget periodically. 
Performance measurement of managers can be used to determine their salary, bonus, task and promotion. Each measurement could urge them to try their best to achieve the targets which was set in evaluation. Evaluation indicators are divided into financial ones and non-financial ones. Incentive mechanism is an important part of management. It would reward actors with what they expect, if the action could help for achieving goals.

Except the management methods above, the controlling part in quality cost management, the funds operation and human capital operation is indispensable. All of them should be considered in different strategy. Additionally, there are some other cost management methods, such as kaizen costing, cost-volume-profit analysis, pricing and profitability analysis, and inventory management. But their core ideas are embodied in the cost managements above, so we choose them to be representatives.

\section{EVALUATION CRITERION OF COST MANAGE- MENT CONTROLLING SYSTEM}

Cost management evaluation aims at assisting to establish competitive advantage. Therefore, strategic cost management system evaluation is based on competition strategy. Different criterion should be used in different strategy. In the condition of low-cost strategy, the requests for technology and resource are commitment of large capital expenditures, advanced production technology, strict work discipline, general product design and low-cost sales channels; the requests for organization are strict cost control, high frequency detailed reports and reward system strictly on the basis of index. In the condition of differentiation strategy, the requests for technology and resource are strong marketing, advanced production technology, creative ability, good reputation for quality, good at improving and coordinate ability; the requests for organization are coordinating various functional departments, ability to attract various talents, attaching great importance to the subjective judgment and reward no index.

\subsection{Determination of Population and Individual}

All the cost management methods classified in different strategies are determined as population, each method is an individual. Details are shown in Table $\mathbf{1}$.

So, population $=[$ origin management; activity improvement; activity chain optimization; value engineering; cost variance analysis; budget management; performance evaluation system and incentive mechanism, quality cost management; funds operation; human capital operation].

\subsection{Classifying and Assignment}

According to the different concerns and requirements in different strategy, cost management methods are classified into five grades: A, B, C, D, E. A value was assigned to each grade by expert scoring method. The results are shown in Table 2.

\subsection{Individual Frequency Statistics}

The cost management methods used in enterprise were analyzed to solve the following problems:
Which cost management methods have been adopted in enterprise and what is the total number;

Which cost management methods shouldn't be considered because of the characteristics of industry or special cases, the cost management methods without considering are deemed as adopted and what is the total number;

Which cost management methods should be adopted but had not been adopted and what is the total number.

\subsection{Calculating the Score and Conclusion}

According to the basic score of each grade and the rating capacity(projects number in each grade), we calculated aggregate score of each grade in different strategy, the sum of aggregate scores of all grades, and the arithmetic average of aggregate score of each grade. Then we calculated the difference between aggregate score of each grade and the arithmetic average of aggregate score of each grade, and summarized the differences. The sum is score of cost management controlling system. If the score $>0$, cost management controlling system made positive contribution to strategy; If the score $<0$, cost management controlling system made negative contribution to strategy. Formulas are shown below.

$$
\begin{aligned}
& X_{i}=n_{i} \times x_{i} \\
& X_{t}=\sum X_{i} \\
& X_{a}=\frac{X_{t}}{5} \\
& X_{i e}=n_{i e} \times x_{i} \\
& I=\sum\left(X_{i e}-X_{a}\right)
\end{aligned}
$$

In the formulas, $\mathrm{i}=\mathrm{A} 、 \mathrm{~B} 、 \mathrm{C} 、 \mathrm{D} 、 \mathrm{E} ; \mathrm{X}_{\mathrm{i}}$ is the basic score of each grade; $n_{i}$ is projects number in each grade; $n_{i e}$ is projects number in each grade in enterprise; $X_{i}$ is aggregate score of each grade in different strategy; $X_{i e}$ is aggregate score of each grade in enterprise; $X_{t}$ is the sum of aggregate scores of all grades; $X_{a}$ is The arithmetic average of aggregate score of each grade; $I$ is the score of cost management controlling system.

\section{APPLICATION OF EVALUATION OF COST MANAGEMENT CONTROLLING SYSTEM}

The cost controlling methods in the fourth oil recovery company of Daqing Oilfield are shown as follows:

(1) Origin management belongs to cost avoidance by strengthening regulation and monitoring. The activities of origin management consist of strengthening utilities management, preventing the power loss, optimizing the operation of power grids, utilizing advanced energysaving technology, adjusting the structure of injection and production, tracking the pipe pressure of water injection system, adjusting the running water injection pump, controlling the dosage of cooling water, supervising data transfer, applying salt resistant polymer positively in waste water recovery system; 
Table 1. Cost control methods for different strategy.

\begin{tabular}{|c|c|c|c|}
\hline \multirow{2}{*}{ Strategy } & \multicolumn{3}{|c|}{ Cost Control Methods } \\
\hline & Cost Avoidance Methods & Cost Control Methods & Other Methods \\
\hline Low-cost Strategy & $\begin{array}{l}\text { origin management; activity improve- } \\
\text { ment; } \\
\text { activity chain optimization; } \\
\text { value engineering }\end{array}$ & $\begin{array}{c}\text { cost variance analysis; } \\
\text { performance evaluation system and } \\
\text { incentive mechanism; } \\
\text { budget management }\end{array}$ & $\begin{array}{c}\text { quality cost management; } \\
\text { human capital operation; } \\
\text { funds operation }\end{array}$ \\
\hline Differentiation Strategy & $\begin{array}{l}\text { origin management; activity improve- } \\
\text { ment; } \\
\text { activity chain optimization; } \\
\text { value engineering; } \\
\text { human capital operation }\end{array}$ & $\begin{array}{l}\text { cost variance analysis; } \\
\text { performance evaluation system and } \\
\text { incentive mechanism; } \\
\text { quality cost management }\end{array}$ & $\begin{array}{l}\text { budget management; } \\
\text { funds operation }\end{array}$ \\
\hline
\end{tabular}

Table 2. Classifying of cost control methods for different strategic.

\begin{tabular}{|c|c|c|}
\hline Grade & \multicolumn{2}{|r|}{ Strategy } \\
\hline $\mathrm{B}$ & $\begin{array}{l}\text { cost variance analysis; } \\
\text { performance evaluation system and incentive mechanism }\end{array}$ & $\begin{array}{l}\text { origin management; marketing value engineering; designing value engineer- } \\
\text { ing(sentimental concept and emphasis on material desire and glamour; Inno- } \\
\text { vative concept and emphasis on glamour and spiritual desire; high-grade } \\
\text { concept and emphasis on the spiritual desire and practicability); quality cost } \\
\text { management; human capital operation }\end{array}$ \\
\hline $\mathrm{C}$ & $\begin{array}{l}\text { manufacturing value engineering; } \\
\text { budget management }\end{array}$ & $\begin{array}{l}\text { cost variance analysis; } \\
\text { performance evaluation system and incentive mechanism }\end{array}$ \\
\hline
\end{tabular}

(2) Activity chain optimization belongs to cost avoidance by cutting some costs. These activities are not annual such as replacing the tubing, replacing the rod, housing repairs and replacement of pumping unit model. So these items should be cut from budget, more capital could be used in urgently needed activities.

(3) Activity improvement belongs to cost avoidance by promoting the transformation of scientific and technological achievements. The activities of activity improvement consist of promoting the transformation of geologic research, the application of mature technologies.

(4) Value engineering belongs to cost avoidance by two ways. One is transferring cost, such as transferring surplus capital of old oilfields reconstruction into payment for electric well instead of motor-pumped well, motorpumped well instead of electric well, screw pump instead of pumping unit, oil pumping well instead of water well, the other is recycling, such as repairing the old equipment and using waste materials.
(5) A separate cost budget department was set up and cost budget for reasonable budgets and forcing control were strengthened.

(6) Cost assessment system was implemented strictly, an incentive mechanism was established, a contract system was set up, and cost comparison activities were organized.

(7) Capital operation was emphasized to maximize costeffectiveness of funds.

Based on the analysis of cost controlling methods in the fourth oil recovery company of Daqing Oilfield, we can establish that these methods meet the requirements of low-cost strategy. Requirements of grade A have been met, because of single variety and short supply. Marketing value engineering and designing value engineering have not been considered and origin management belonging to cost avoidance has been used in type (1). Requirements of grade B have been met, because of the particularity of products, cost variance analysis which made little contribution to resources exploita- 
tion has not been considered. Performance evaluation system and incentive mechanism have been used in type (6). Requirements of grade $\mathrm{C}$ have been met. Manufacturing value engineering belonging to cost avoidance has been used in type (4) and budget management has been used in type (5). Requirements of grade D have been met. Activity improvement and activity chain optimization have been used in types (1) and (3). Requirements of grade E have basically been met. The fourth oil recovery company of Daqing Oilfield is weak in quality cost management due to single variety and the high purity of crude oil. Theory and technology are equally important for mining, resulting in equally important different departments and employees. Funds operation has been used in type(7).

Table 3. Values of cost management controlling system.

\begin{tabular}{|c|c|c|c|c|}
\hline \multirow{2}{*}{ Grade } & \multicolumn{4}{|c|}{ Score } \\
\hline & $X_{i}$ & $X_{a}$ & $X_{i e}$ & $I$ \\
\hline A & 50 & \multirow{5}{*}{20} & 50 & \multirow{5}{*}{4.17} \\
\hline B & 25 & & 25 & \\
\hline $\mathrm{C}$ & 17.5 & & 17.5 & \\
\hline D & 8.75 & & 8.75 & \\
\hline E & 8.75 & & 2.92 & \\
\hline
\end{tabular}

I 0 , the conclusion is cost management controlling system of the fourth oil recovery company of Daqing Oilfield made positive contribution to strategy.

Because the fourth oil recovery company of Daqing Oilfield was evaluated on cost management controlling system for the first time in the paper, there is no reference indicator. According to the rule that each grade score equals to the sum of subordinate scores, we defined the score of each grade: A50, B-25, C-17.5, D-8.75, E-8.75. The score of cost management controlling system is shown in Table $\mathbf{3}$ :

\section{CONFLICT OF INTEREST}

The authors confirm that this article content has no conflict of interest.

\section{ACKNOWLEDGEMENTS}

This work is supported by the Science and Technology Project of Heilongjiang Agricultural Reclamation Department, China (No.HNK125A-14-14), Soft Science Project of Heilongjiang, China (No.HNK125A-14-05), and Social Science Project of Daqing, China (No.DSGB2014087).

\section{REFERENCES}

[1] Palipo, "Management perspective: Analysis and evaluation of Enterprise", Dalian: Northeast Finance and Economics University Press, pp. 35-39, 1995

[2] R.N. Anthony, "The Management Control Function", USA: Harvard Business School Press, 1988.

[3] ASQC, "Quality Cost Committee. Guide for Reducing Quality Cost" ASQC, $2^{\text {nd }}$ ed, pp. 685-756, 1987.

[4] A.H. Greehe and P. Flentov, "Managing performance: Maximizing the benefit of activity-based costing" Emerging Practices in Cost Management, pp. 435-554, 1991.

[5] P.B.B. Turney, "Activity based costing", Management Accounting Handbook, $4^{\text {th }}$ ed., C. Drury, Butterworth-Heinemann and CIMA, pp. 237-344, 1992.

[6] P.B.B. Turney, "Common cents: The ABC performance breakthrough. Portland", Cost Technology, pp. 13, 1992.

[7] P.B.B. Turney, "Activity-based management-ABM puts $\mathrm{ABC}$ information to work", Management Accounting (IMA), pp. 78-99, 1992.

[8] Y.T. Mak, and M.L. Roush, "Flexible budgeting and variance analysis in an activity-based costing environment", Accounting Horizons, vol. 8, no. 2, pp. 23, 1994.

[9] L.B. Dorothy, "Innovation and Knowledge," China: Xinhua Publishing House, 2000.

[10] X. Yu, "The Frame of ABM based management system," Contemporary Finance \& Economics, vol. 4, pp. 23, 1994.

[11] H. Huang, "Assessment of enterprise cost management," Industrial Technology Economics, vol. 17, no. 3, pp. 15, 1998.

[12] X. Guo, G. Yang, L. Kuang, and L. Guo, "Oilfield enterprises evaluation model of cost management", Journal of Daqing Petroleum Institute, vol. 23, no. 3, pp. 35, 1999.

[13] Q. Feng, "The performance evaluation of small-and-medium-sized enterprises cost management" ZheJiang Fiscal, Taxation and Accounting, vol. 8, pp. 23, 2002.

[14] J.Lu, Z. Zhang and X. Zhou, "Comprehensive analysis and evaluation of construction enterprise cost" Journal of Masonry International, vol. 35, no. 6, pp. 43, 2002.

[15] S.Q. Chen, "Idea project of target costing in Japan," Foreign Economies and Management, vol. 1, no. 7, pp. 22, 1977.

[16] W. Xiao, "Essential questions of activity based management," Hubei Social Sciences, vol. 2, pp. 20-23, 2004.

[17] P.B.B. Turney, "Second-Generation Architecture" Handbook of Cost Management, 1992.

[18] Dickey R.I. Accountant's Cost Handbook, USA: John Wiley \& Sons, 1960.

[19] R.S Kaplan, A.A Atkinson and C.J. Lv, Advanced Management Accounting, China: Dongbei University of Finance \& Economics Publishing House, pp. 125-139, 1999.

[20] R.N. Anthony, "Management Accounting Text and Cases", $3^{\text {rd }}$ Ed. USA: Richard D. Irwin, INC., pp. 33-35, 1964.

[21] A. Belkaoui, "Conceptual Foundations of Management Accounting, USA: Addison-Wesley Publishing Company, pp. 9-11, 1981.

[22] J.A. Brimson, "Activity accounting - an activity-based costing approach, USA: John Wiley \& Sons, pp. 35-56, 1991.

[23] R.S. Kaplan, "Flexible budgeting in activity-based costing framework," Accounting Horizons, vol. 8, no. 2, pp. 34, 1994.

(C) Guo and Zhang; Licensee Bentham Open.

This is an open access article licensed under the terms of the (https://creativecommons.org/licenses/by/4.0/legalcode), which permits unrestricted, noncommercial use, distribution and reproduction in any medium, provided the work is properly cited. 